\title{
Práticas Pedagógicas e Habilidades Sociais: Possibilidade de Pesquisa de Intervenção com Professores
}

\author{
Tatiane Cristina Rodrigues Lessa \\ Universidade Federal de São Carlos - São Carlos - SP - Brasil \\ Natalia Costa de Felicio \\ Universidade Federal de São Carlos - São Carlos - SP - Brasil \\ Maria Amélia Almeida \\ Universidade Federal de São Carlos - São Carlos - SP - Brasil
}

\section{Resumo}

As habilidades sociais são de extrema importância dentro das práticas pedagógicas, pois permitem a interação adequada em todo o contexto escolar. Pensando na subclasse específica de dar feedback, este estudo objetivou verificar se o ensino específico dessa subclasse de habilidades sociais pode auxiliar ou modificar a frequência de respostas dessa habilidade e interferir no número de solicitações dos alunos durante o período de aula. O estudo caracteriza-se por utilizar um delineamento experimental do tipo ABA e teve como participante uma professora de escola pública estadual de uma cidade do interior do Estado de São Paulo. Para a coleta de dados foram utilizados três protocolos onde eram computados os números de feedbacks e solicitações realizados por professora e alunos, respectivamente. Realizaram-se 13 sessões e o critério para o final das intervenções foi o aumento de $60 \%$ do número de feedbacks iniciais. Como resultados, verificou-se o aumento do número de feedbacks positivos. Palavras-Chave: Feedback; formação de professores; métodos experimentais.

\section{Pedagogical Practices and Social Skills: Possibility of Intervention Research with Teachers}

\begin{abstract}
Social skills are extremely important within pedagogical practices, as they allow adequate interaction throughout the school context. Considering the specific subclass of feedback, this study aimed to verify if the specific teaching of this subclass of social skills can help or modify the frequency of responses of this ability and interfere in the number of requests of the students during the class period. The study is characterized by using an ABA-type experimental design and had as participant a teacher of a state public school in a city in the countryside of the State of São Paulo. For data collection, three protocols were used to compute the numbers of feedbacks and requests made by teacher and students, respectively. There were 13 sessions and the criterion for the end of the interventions was the $60 \%$ increase in the number of initial feedbacks. As results, there was an increase in the number of positive feedbacks.
\end{abstract}

Keywords: Feedback; teacher education; experimental methods.

\section{Prácticas Pedagógicas y Habilidades Sociales: Posibilidad de Investigación de Intervención con Profesores}

\begin{abstract}
Resumen
Las habilidades sociales son de extrema importancia dentro de las prácticas pedagógicas, pues permiten la interacción adecuada en todo el contexto escolar. Pensando en la subclase específica de dar feedback, este estudio tuvo por objetivo verificar si la enseñanza específica de esa subclase de habilidades sociales pode ayudar o modificar la frecuencia de respuestas de esa habilidad e interferir en el número de solicitaciones de los alumnos durante el período de clase. El estudio se caracteriza por utilizar un delineamiento experimental del tipo ABA y tuvo como participante una profesora de escuela pública estadual de una ciudad del interior del Estado de São Paulo. Para la recolecta de datos se utilizó tres protocolos en que se computó los números de feedbacks y solicitaciones realizados por profesora y alumnos, respectivamente. Se realizaron 13 sesiones y el criterio para el final de las intervenciones fue el aumento del $60 \%$ del número de feedbacks iniciales. Como resultados, se verificó el aumento del número de feedbacks positivos.
\end{abstract}

Palabras clave: Feedback; formación de profesores; métodos experimentales. 


\section{Introdução}

Dentre as diversas áreas presentes no contexto escolar têm-se as práticas pedagógicas. Estas têm se tornado assunto de extrema importância no contexto educacional uma vez que podem auxiliar a dinâmica da sala de aula tornando-a mais proveitosa e benéfica aos alunos. A possibilidade de criação de diálogos entre essa e outras áreas, especialmente às relacionadas à psicologia, são inúmeras. Desta forma, o presente trabalho terá como proposta discutir e aproximar as práticas pedagógicas da área específica em psicologia chamada habilidades sociais. Apesar de essa relação ser pouco explorada, as duas áreas possuem diversos aspectos comuns cujo foco é o benefício do aluno, professores e contexto escolar como um todo.

A prática pedagógica pode ser entendida como uma prática social complexa, a qual acontece em diferentes espaços e tempos da escola, no cotidiano de professores e alunos nela envolvidos e, de modo especial, na sala de aula, mediada pela interação professor-aluno-conhecimento (Caldeira \& Zaidan, 2011).

O trabalho docente, de acordo com Cunha (2011), envolve três etapas importantes: (1) observação, (2) avaliação, e (3) mediação. A observação caracteriza-se por ser uma atividade de pesquisa que consiste em registrar e perceber o que se vê, sem a preocupação inicial da interpretação dos dados e, ainda, da necessidade em registrar as facilidades e dificuldades dos alunos frente a determinada situação. A avaliação objetiva compreender o comportamento dos alunos diante dos instrumentos de ensino e aprendizagem; é um mecanismo de melhoria nas decisões futuras do professor, pois tem como enfoque os objetivos e os passos que serão dados em direção ao progresso dos mesmos. Por fim, a mediação constitui-se pela interlocução entre o aluno e o saber a ser conquistado; transformar a intenção de ensinar em prática docente e criar vínculos entre o professor, aluno e ambiente escolar.

Tais etapas irão repercutir em como o professor planeja, organiza, reflete e conduz a sua aula e, nesse sentido, também é necessária a reflexão sobre temas que envolvem a formação do professor e sua forma de ensino. Para Marques (2001) essa reflexão deve ter em mente o saber fazer e o saber pensar, a fim de que haja uma prática inovadora na qual o docente compreenda o seu fazer e, assim, possa ampliar sua prática de ensino e transmitir, dessa forma, o conhecimento escolar acumulado.

Ademais, é preciso oferecer ao professor uma formação de qualidade para que este possa respaldar sua prática pedagógica em sala de aula, o que poderá acarretar na construção de uma consciência crítica sobre os processos de ensino e aprendizagem (Libâneo, 2013). Nesse sentido, Moroz e Luna (2013) indicam que "o professor é aquele que modifica o próprio comportamento para facilitar a aprendizagem do outro" (p.117) sendo responsável por planejar e organizar o ambiente escolar de forma a favorecer esse processo.

Portanto, todos os contextos educativos que envolvem uma sala de aula são de extrema importância, assim como os comportamentos que permeiam todos os indivíduos que a frequentam. Dessa forma, surge a possibilidade de ampliação e aprimoramento desses comportamentos por meio das habilidades sociais.

As habilidades sociais são compreendidas por Del Prette e Del Prette (2013a) como "diferentes classes de comportamentos sociais de um repertório do indivíduo, que contribuem para a competência social, favorecendo um relacionamento saudável e produtivo com as demais pessoas" (p. 31). Nessa direção, Caballo (2014) aponta que uma vez que "os padrões de comunicação variam de forma ampla entre culturas e dentro de uma mesma cultura, dependendo de fatores como idade, sexo, classe social e educação" ( $p$. 4) esse trabalho remete à importância dessa temática na cultura escolar.

Dentro desta perspectiva, segundo Del Prette e Del Prette (2013a), "essa aprendizagem depende das condições que a criança encontra nesses ambientes, o que influi sobre a qualidade de suas relações interpessoais subsequentes" (p.51). Portanto, entende-se a escola como um espaço privilegiado para um conjunto de interações sociais educativas e, dessa forma, a qualidade dessas interações constituem importantes processos educacionais (Del Prette $\&$ Del Prette, 2013b). Por outro lado, percebe-se que

os professores costumam criticar e elogiar seus alunos, mas, na maioria das vezes, as críticas e elogios apresentam características muito negativas. Grande parte das críticas e elogios é do tipo generalizante, ou seja, em vez de identificar o(s) comportamento(s) que se pretende destacar, o professor faz referência excessivamente abrangente (Del Prette \& Del Prette, 2013a, pp. 65-66).

Nesse sentido, faz-se necessário o auxílio a professores para mediar de maneira eficaz as relações que permeiam o contexto escolar. Por isso, destacam-se dentro do campo das habilidades sociais, as Habilidades Sociais Educativas (HSE), que são "aquelas intencionalmente voltadas para a promoção do desenvolvimento e da aprendizagem do outro, em situação formal ou informal" (Del Prette \& Del Prette, 2013b, p. 95). Essas podem ser elencadas, conforme sugerido por Bolsoni-Silva (2010) em três tipos: (1) HSE de Comunicação, (2) HSE de Expressividade e Enfrentamento, e (3) HSE de Estabelecer Limites.

Na primeira, Bolsoni-Silva (2010) aponta que o professor deverá perceber o momento certo, local, estado de humor, tempo para se iniciar, manter e encerrar uma conversa com seus alunos. Na segunda, a necessidade advém do saber se expressar carinhosamente por meio de palavras e gestos, além de elogiar no momento adequado e aprender a lidar com diferentes pontos de vista. Por fim, para o estabelecimento de limites, o professor deverá aprender a lidar com críticas, estabelecer regras, recusar determinados pedidos, agir preventivamente com o objetivo de evitar problemas de comportamento, admitir erros e pedir desculpas, dentre outros.

Assim, frente a essa complexidade advém a importância das habilidades sociais e habilidades sociais edu- 
cativas. O presente relato irá destacar uma das classes de habilidades sociais discutidas na literatura: o dar feedback. Segundo Del Prette e Del Prette (2012), essa designação foi emprestada da eletrônica pelas Ciências da Computação e, apesar das diferenças entre as áreas, é mantido o significado de retroalimentação. Assim, segundo esses autores, o feedback, nas relações sociais, mantém esse conceito ajustando-se ao padrão de melhor manutenção ou alteração de um comportamento.

Esses padrões de manutenção e alteração de comportamentos são de extrema importância no contexto escolar uma vez que neste vivencia-se um conjunto de interações sociais que objetivam a educação dos seus envolvidos (Del Prette \& Del Prette, 2013b). "Logo, a qualidade das interações sociais presentes na educação escolar constitui um componente importante na consecução de seus objetivos e no aperfeiçoamento do processo educacional" (Del Prette \& Del Prette, 2013b, p.54).

Além disso, inúmeros estudos apontam que comportamentos socialmente competentes contribuem para a meIhoria de qualidades nas relações interpessoais, qualidade de vida e autoestima sendo, portanto, importante fator de proteção, especialmente para as crianças e, também, podem contribuir, dentre outros, para o bom rendimento acadêmico de escolares (Del Prette, Ferreira, Dias, \& Del Prette, 2015).

Desta forma, "utilizado de maneira intencional, o feedback pode ser entendido como uma descrição verbal ou escrita sobre o desempenho de uma pessoa (Del Prette \& Del Prette, 2013b, p. 68) e que "enquanto procedimento de ensino-aprendizagem, o feedback permite que a pessoa sob treinamento perceba como se comporta e como esse comportamento afeta seu interlocutor" (Del Prette \& Del Prette, 2013b, p. 69).

Vale a ressalva que o feedback pode ser do tipo positivo ou negativo e que "é importante considerar o impacto do feedback positivo na manutenção e aperfeiçoamento dos aspectos desejáveis do desempenho" (Del Prette \& Del Prette, 2013b, p.69). Assim, Del Prette e Del Prette (2013b) apontam que apesar de o feedback negativo ser mais prevalente em nossa cultura, deveria ser substituído pelo positivo pois "evita ressentimentos e reações defensivas..., dispõe a pessoa a ouvir com mais atenção as observações feitas pelo interlocutor..., motiva a pessoa a investir no aperfeiçoamento dos aspectos valorizados, aumenta a probabilidade dos desempenhos valorizados voltarem a ocorrer" (Del Prette \& Del Prette, 2013b, p.69).

Destacam-se, ainda, para o presente trabalho, dois conceitos importantes das habilidades sociais chamados de automonitoria e desempenho social. Del Prette e Del Prette (2013b) definem o primeiro como uma "habilidade metacognitiva e afetivo-comportamental pela qual a pessoa observa, descreve, interpreta e regula seus pensamentos, sentimentos e comportamentos em situações sociais" (p.62). Já o desempenho social é definido como a "capacidade de articular pensamentos, sentimentos e ações em função dos objetivos pessoais e demandas da situação e da cultura, gerando consequências positivas para o indivíduo e para a sua relação com as demais pessoas" (Del Prette \& Del Prette, 2013a, p. 33). Acredita-se, também, que esses conceitos são de fundamental importância dentro do contexto escolar e para a atuação dos professores, sendo, portanto, considerados bases importantes para o feedback positivo.

Dessa forma, acredita-se que tais conceitos seriam base para uma intervenção efetiva na escola e uma boa prática pedagógica pois poderiam proporcionar ao professor a reflexão sobre os seus comportamentos e como estes impactariam, diretamente, ao padrão de respostas de seus alunos. Entende-se, aqui, que "o investimento da escola na promoção de habilidades sociais pode ser defendido com base em três argumentos: a função social da escola; as evidências de relação entre habilidades sociais e desempenho acadêmico; as políticas de inclusão" (Del Prette \& Del Prette, 2013a, p. 63)

Assim, reconhece-se que são praticamente inexistentes os estudos que abordam os métodos experimentais e o treinamento de professores focados em práticas pedagógicas e habilidades sociais. Del Prette e Del Prette (1998) apresentaram um estudo de caso baseado em análises de filmagens de um Programa de Desenvolvimento Pessoal e Profissional (PRODIP). Esse trabalho teve como objetivo promover a habilidade de estruturação de interações sociais educativas em sala de aula por parte do professor e, como resultados, trouxe a efetividade desse tipo de programa de intervenção.

O estudo caracterizado como uma pesquisa intervenção de Rosin-Pinola (2009) teve como foco aprimorar o repertório de habilidades sociais educativas dos professores de alunos com necessidades educacionais especiais. Na pesquisa realizou-se a intervenção em momentos grupais, em que eram tratados temas e assuntos comuns e individuais, cujo objetivo era promover habilidades sociais educativas específicas no repertório de cada professor. Os resultados evidenciaram os efeitos positivos e funcionais no repertório de habilidades sociais educativas das professoras após a intervenção, bem como mudanças positivas no repertório geral dos alunos.

Del Prette e cols. (2015) apontaram um estudo cujo foco das pesquisas no trabalho com professores tem sido no sentido de promover o desenvolvimento socioemocional das crianças. Segundo esses autores, inúmeros estudos estão disponíveis para replicação e que, de maneira geral, eles se assemelham aos desenvolvidos com adultos e habilidades sociais, com a peculiaridade que os que envolvem professores têm por foco as habilidades sociais educativas e o objetivo final de capacitar os agentes educadores na tarefa de promover, em ambiente escolar, as habilidades sociais dos alunos.

Dessa forma, o presente trabalho teve como principal objetivo responder à pergunta de pesquisa se o ensino específico de uma classe de habilidades sociais poderia auxiliar diretamente na frequência de respostas dessa habilidade, a qual se desejava medir. Ou seja, o ensino e a intervenção baseada na técnica específica de feedback poderiam ampliar o número de feedbacks ofertados por um(a) professor(a) no 
contexto de sala de aula? E, ainda, se a quantidade de solicitações dos alunos para a professora seria modificada de acordo com o número de feedbacks ofertados.

\section{Método}

O estudo caracteriza-se por utilizar um delineamento experimental tendo o sujeito como seu próprio controle, do tipo ABA (Linha de Base - A1, Intervenção - B, Retirada Intervenção - A2). Segundo Gast (2010), este delineamento é um dos mais simples para demonstrar causa e efeito das relações. Inicialmente o comportamento a ser investigado é medido por meio da linha de base que deve ocorrer por "no mínimo três dias consecutivos ou até se estabilizar" (Gast, 2010 , p. 243). Em seguida, inicia-se o processo de intervenção e, após a variável dependente se estabilizar a condição da linha de base A2 (Retirada da Intervenção) é novamente introduzida. Dessa forma, a variável dependente diz respeito ao número de feedbacks e a variável independente à intervenção, no caso, as orientações realizadas à professora.

Sendo assim, a linha de base (A1) deste estudo constituiu-se por repetidas observações e registros de dados durante três dias. Esses eram contabilizados de acordo com uma tabela desenvolvida pelas pesquisadoras, tendo como base o número de solicitações requeridas dos alunos e o número de feedbacks tanto positivos como negativos fornecidos pela professora. Vale a ressalva que a denominação "solicitação" foi utilizada para comportamentos verbais específicos dos alunos direcionados à professora (quando chamada pelo nome, por "professora" ou "pro") ou para comportamentos gestuais (levantar a mão).

Após a linha de base $\mathrm{A} 1$ deu-se início à fase de intervenção $(B)$ constituindo-se pelas repetidas intervenções das pesquisadoras com o sujeito da pesquisa. Para a interrupção dessas utilizou-se o critério dos comportamentos de feedback serem superiores a $60 \%$ quando comparados a esses na linha de base (A1). Em seguida, foi reintroduzida a linha de base (A2 - Retirada da Intervenção) com os mesmos critérios de A1. O número de feedbacks e solicitações dos alunos foi numerado por ambas as pesquisadoras $e$ retiradas as médias a fim de calcular o número de respostas realizadas pela professora.

Os cuidados éticos da pesquisa foram tomados para promover a confiabilidade dos dados e informações coletadas bem como a identidade do participante e da instituição da pesquisa. A investigação foi desenvolvida em uma escola pública estadual de uma cidade de médio porte do interior do Estado de São Paulo, a qual contempla os níveis Fundamental I e II. Participou da pesquisa uma professora, com 39 anos de idade, que lecionava para o $5^{\circ}$ ano do Ensino Fundamental.

Para o registro foram utilizados cadernos, lápis e borracha para preenchimento dos diários de campo e protocolos no momento das aulas, a fim de auxiliar na coleta e sistematização dos dados. Como instrumentos de coleta de dados foram utilizados três protocolos criados pelas pesquisadoras, os quais foram elaborados para as fases de Linha de Base (A1), Intervenção (B) e Linha de Base (A2). Nesses protocolos eram contabilizados os números de feedbacks dados pela professora e o número de solicitações realizadas pelos alunos no prazo de uma hora por registro; constando a data e hora da realização da observação. Também foi computado o número de alunos presentes em sala de aula e a disciplina que estava sendo lecionada.

Foram realizadas 13 sessões, totalizando um mês de observação sendo estas divididas em: 3 sessões de linha de base (A1), 7 sessões de intervenção (B) e 3 sessões linha de base (A2). As observações ocorriam no início do turno escolar, previamente ao intervalo (entre 7 h00 e 9h30).

Neste estudo foram consideradas como intervenções as sessões de orientações realizadas com a professora sempre após uma hora de observação e que dependiam da sua disponibilidade. Durante as observações não era realizada nenhuma interação com os alunos ou com a professora; assim, as pesquisadoras ficaram restritas às anotações das medidas a serem pesquisadas.

Nas intervenções as pesquisadoras faziam apontamentos de certos aspectos observados durante as aulas ministradas, visando sempre a importância do feedback positivo da professora aos seus alunos. Tais apontamentos relacionavam-se aos comportamentos de solicitação emitidos pelos alunos e a resposta da professora a estes (feedback). Também, buscou-se nesses momentos que a professora pudesse refletir sobre a importância de modificar o número de feedbacks negativos por positivos e os comportamentos de seus alunos frente a essa conduta.

Os dados coletados foram analisados de forma quantitativa e qualitativa, sendo a primeira referente aos protocolos utilizados e a segunda pela análise dos dados dos diários de campo.

\section{Resultados}

Ao longo do estudo a média de frequência dos alunos foi 20 e as aulas observadas variaram entre Português e Matemática, em sua maioria, e uma aula de Ciências. Vale ressaltar que as observações foram realizadas nas semanas que antecederam uma avaliação que mediria os conhecimentos nas disciplinas específicas de Português e Matemática e, por isso, estas foram as principais aulas ministradas durante o período observado.

No $1^{\circ}$ dia de Linha de Base (A1), a professora ministrou a disciplina de Português, retomando a atividade do dia anterior na qual os alunos deveriam realizar uma carta ao leitor de um jornal/revista. Nessa atividade cada aluno poderia colaborar com a carta que seria realizada de forma oral e, após verbalizações, a professora redigia na lousa o conteúdo final. Nessa aula também foram retomados combinados de regras de sala de aula e da escola com os alunos. Essa atividade poderia proporcionar grande número de feedbacks, pois contava com a interação constante dos alunos para a sua realização; porém, percebeu-se que os feedbacks realizados eram, em sua maioria, de caráter negativo. 


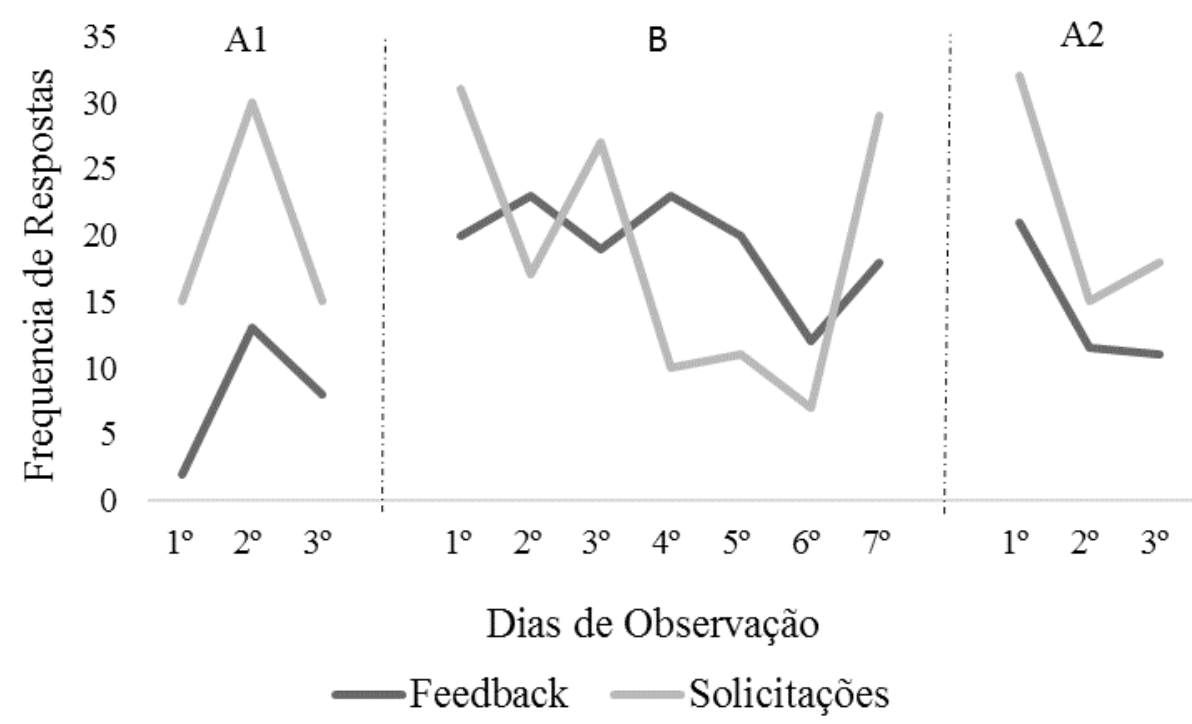

Figura 1. Figura referente à frequência de respostas das linhas de base 1 e $2(A 1, A 2)$ e intervenção (B) dos feedbacks e solicitações.

No $2^{\circ}$ dia de Linha de Base (A1), a disciplina ministrada foi Matemática, a professora estava trabalhando operações matemáticas de divisão do livro didático. Em um primeiro momento, ela auxiliou, de maneira geral, os alunos que apresentavam dúvidas com a resolução das operações. A seguir, verificou de maneira individual se as crianças realizaram as atividades. Na correção em grupo, a professora solicitou que alguns alunos resolvessem as operações na lousa explicando o processo da divisão. Novamente a atividade poderia proporcionar feedbacks, pois alguns alunos estavam Ihe ajudando na correção e acertando as operações; porém, os números destes, apesar de um pequeno aumento nessa sessão, ainda podem ser considerados baixos.

No $3^{\circ}$ dia de Linha de Base (A1) a disciplina observada foi Matemática, a temática da aula era: gênero das músicas para a construção de gráficos, exercício estipulado pelo livro didático. Durante a atividade alguns alunos foram chamados para as aulas de 'reforço' sendo, dessa forma, transferidos para outra sala. Novamente, a professora chamou os alunos para irem à lousa fazer a correção dos exercícios e a construção do gráfico baseado na votação do gênero musical proporcionou a agitação dos estudantes. Essa, porém, foi desconsiderada pela professora, verificando-se o controle da situação por meio de feedbacks negativos. E, assim, os feedbacks foram ainda mais baixos do que os da sessão 2 .

Tendo em vista que os feedbacks positivos nessas três sessões de linha de base (A1) continuavam bem baixos, deu-se início às sessões de intervenção. O primeiro tópico pontuado pelas pesquisadoras foi em relação à quantidade de feedbacks negativos quando comparados aos positivos e enfatizou-se que as condutas inadequadas estavam sendo, em sua maioria, pontuadas e as adequadas não. Sugeriu-se a alteração desse padrão, pois os reforços e feedbacks positivos aos alunos poderiam aumentar a frequência dos padrões de comportamentos adequados e diminuir os inadequados. Tal conduta foi sugerida uma vez que se acredita que o feedback positivo "aumenta a probabilidade dos desempenhos valorizados voltarem a ocorrer (Del Prette \& Del Prette, 2013b, p. 69).

Também, foi explicado brevemente o conceito de automonitoria, sugerindo-se então, que a professora pudesse se recordar dos comportamentos que eram emitidos por ela em sala de aula. Acredita-se que o automonitoramento poderia refletir, diretamente, na mudança de comportamento da professora uma vez que, conforme apontam Del Prette e Del Prette (2013b), "aquelas pessoas que aprendem a monitorar a si próprias são geralmente conscientes de suas emoções, pensamentos e comportamentos, conhecem suas potencialidades e pontos vulneráveis, planejam metas pertinentes aos seus recursos e alteram seu desempenho quando isso se faz necessário" (p.62).

Vale ressaltar que tal procedimento também vai ao encontro do ressaltado por Cunha (2011), de que o conceito de uma boa prática pedagógica sugeriria as técnicas de observação, avaliação e mediação. Desta forma, verificou-se que, após o primeiro dia da intervenção, o padrão de comportamento da professora mudou consideravelmente. Esta passou a apontar feedbacks em maior número sendo que, apesar de o protocolo não ter como objetivo separar os dois tipos de feedbacks, as pesquisadoras verificaram que os negativos diminuíram e os positivos aumentaram.

Assim, os sete dias de intervenção mantiveram o mesmo padrão. Foram realizadas as disciplinas de Português e Matemática, nas quais os conteúdos assemelharam-se: operações matemáticas de multiplicação e divisão, e leitura de histórias pelos alunos. Percebeu-se, ao longo da pesquisa, que as aulas de matemática contavam com maior número de feedbacks quando comparada às de português. Tal dado 
é significativo na pesquisa, pois pode-se considerar que os feedbacks realizados em áreas de exatas podem ser, culturalmente, mais considerados quando comparados aos de português. Por exemplo, um feedback possível nas aulas de Português poderia ser "percebi que sua leitura está mais clara e com tom de voz adequado, parabéns!" ou, caso necessitasse de uma alteração de comportamento: "percebi que você leu um pouco baixo. Você poderia tentar aumentar o tom de voz para que seus colegas do fundo lhe escutem?".

Em relação à parte quantitativa dos dados, estes foram agrupados de acordo com a figura a seguir. A Figura 1 apresenta a comparação entre o número total de feedbacks e solicitações nos dias de observação entre os períodos de linha de base (A1), intervenção $(B)$ e linha de base (A2), respectivamente. No eixo horizontal têm-se os dias observados e no eixo vertical a frequência de respostas da professora e dos alunos (feedbacks e solicitações).

Pela Figura 1 pode-se perceber um aumento do número de feedbacks realizados pela professora no transcorrer das observações e intervenções, exceto pelos $5^{\circ} \mathrm{e}$ $6^{\circ}$ dias de intervenção, em que houve uma queda sem, entretanto, haver sobreposição de dados, quando comparados com a fase de linha de Base A1. Todavia, na sétima sessão o número de feedbacks voltou a subir. Assim, destaca-se que o critério estabelecido para a interrupção da intervenção foi atingido logo após o primeiro dia de sua implementação; entretanto, optou-se pela manutenção desta por 7 dias consecutivos. Destaca-se, ainda, que o mesmo padrão, acima de $60 \%$ comparado à $\mathrm{A} 1$, manteve-se até o último dia da intervenção. Assim, quando foi introduzida a linha de base A2, (Retirada da Intervenção) o padrão se manteve, apesar da redução quando comparada às sessões de intervenção. Talvez a fase de intervenção pudesse ter se mantido por mais alguns dias para garantir que a professora pudesse emitir mais feedbacks após a retirada da intervenção. Em relação às solicitações dos alunos, pode-se perceber que não apresentaram um padrão fixo, variando ao longo de toda a pesquisa.

Observou-se, ao longo de toda a pesquisa, que a professora apresentava um número de feedbacks quase sempre inferior ao número de solicitações dos alunos, apesar da melhora considerável destes conforme se dava a intervenção. Na linha de base A1 notou-se que a maioria dos feedbacks proporcionados era negativa, ou seja, a professora notava e reforçava muito mais os comportamentos inadequados dos alunos do que os adequados.

No primeiro dia de intervenção, as pesquisadoras pontuaram tal questão à professora e propuseram que os feedbacks deveriam ser reforçados, em sua maioria, quando positivos e que tal conduta auxiliaria especialmente no mau comportamento dos alunos referido pela professora. Assim, a pesquisa salientou a importância da técnica de feedback para o ensino-aprendizagem e do impacto que este poderia ter na manutenção e desempenho de comportamentos desejáveis, conforme mencionado por Del Prette e Del Prette (2013b).

Outro ponto a ser considerado foi a percepção por parte das pesquisadoras quanto ao número de solicitações nas aulas por parte dos alunos. Percebeu-se que foram inferiores nas aulas de Português quando comparadas às aulas de Matemática. Acredita-se que essa característica seja comum ao próprio tipo de atividade fornecida, pois nas aulas de Matemática os alunos eram solicitados pela professora com maior frequência quando comparado às aulas de Português que, envolviam majoritariamente atividades de leitura, o que pode dificultar a frequência dos feedbacks positivos.

Notou-se que em três dias da intervenção $\left(4^{\circ}, 5^{\circ} \mathrm{e}\right.$ $6^{\circ}$ ) os comportamentos dos alunos e da professora estavam bastante distintos do que vinha sendo observado até aquele momento devido à ocorrência de um problema delicado envolvendo as crianças da sala, segundo relato da professora. De acordo com ela, esse fato conturbou a sua organização e a dos alunos, interferindo no andamento das aulas.

Ao longo de todo o período de intervenção notou-se que a professora estava bastante receptiva às discussões proporcionadas pelas pesquisadoras e mostrava-se atenta a todas as orientações fornecidas.

\section{Discussão}

Acredita-se que o presente trabalho trouxe contribuições importantes para a área de habilidades sociais e práticas pedagógicas, pois foi possível observar a influência benéfica de uma pesquisa de intervenção com base nesses temas e no quanto estes se inter-relacionam. Sugere-se que os trabalhos que envolvam essas duas práticas sejam mais rotineiros em toda a escola visto que auxiliaria os aspectos diretos que envolvem as práticas pedagógicas e as habilidades sociais, e os indiretos como a melhora dos comportamentos inadequados dos alunos.

O estudo contou com algumas limitações e, entre elas, destaca-se a não observação de uma disciplina específica apenas. Como as observações ocorreram em aulas de disciplinas distintas não foi possível discernir se as alterações de frequências de feedbacks ou de solicitações estariam relacionadas entre si ou de acordo com a matéria lecionada. Outro ponto de fragilidade que não pode, entretanto, ser previsto em um contexto de cotidiano escolar, são incidentes que desestabilizam a sala de aula como um todo. Sabe-se que estudos de intervenção estão sujeitos às variáveis intervenientes, entretanto, surge o questionamento se a redução dos comportamentos emitidos por professores e alunos deveu-se, realmente, ao incidente ocorrido ou a outra variável que não pôde ser aqui mensurada.

Também, vale ressaltar, que nesse delineamento ABA, o estudo não tinha como intenção a "reversão" do comportamento da professora, mas, apenas verificar se ela "manteria" seu comportamento de fornecimento de feedbacks aos alunos após a retirada da intervenção. Todavia, como isso não aconteceu, podemos pensar que o professor pode precisar de mais acompanhamento de profissionais, mesmo que esporádicos, no seu dia a dia de sala de aula.

Outro aspecto a ser identificado como limitação da pesquisa foi que o estudo não mediu, especificamente, a mo- 
dificação da frequência de feedbacks positivos e negativos emitidos pela professora sendo esta, portanto, notada apenas nos diários de campo das pesquisadoras. Estas perceberam modificações significativas comparando a frequência de ambos no sentido da substituição do negativo pelo positivo mas, seria importante a medida dessa mudança em futuros estudos apesar dos resultados positivos supracitados.

Assim, sugerem-se futuros estudos que se proponham a observar uma mesma disciplina, ou até mesmo diferentes, mas por uma quantidade maior de tempo na tentativa de minimização de variáveis intervenientes. E, apesar da dificuldade de controle em situações de pesquisa com intervenção, acredita-se que esta foi relevante para a comunidade científica, uma vez que possibilitou a ampliação de intervenções focadas na professora e, especificamente, contemplando temas relevantes como as habilidades sociais em conjunto com as melhores práticas pedagógicas.

\section{Considerações Finais}

Frente ao exposto, são apontadas por este trabalho as modificações relevantes que as habilidades sociais podem proporcionar em ambientes escolares tanto no sentido de contribuir para os processos de ensino-aprendizagem dos alunos de forma geral como na melhora das relações interpessoais como um todo.

Nesse sentido, coloca-se aqui a importância de temáticas que envolvam a formação inicial e continuada de professores unindo-as aos conceitos de habilidades sociais uma vez que conceitos como, por exemplo, o de automonitoria, seriam de extrema importância para que os professores pudessem refletir sobre sua própria prática de acordo com seus comportamentos e aqueles observados em seus alunos. Também, por meio de maior conhecimento nessa área, visto que é ampla e complexa, o professor poderia planejar, organizar, refletir e conduzir a sua aula de uma maneira mais adequada, ampliando assim, suas práticas de maneira geral.

Outro aspecto relevante proporcionado na pesquisa foi a possibilidade de a professora repensar sua competência social a partir da percepção de como esta relacionava-se a fatores emocionais (como o ocorrido com a sala que resultou na queda significativa de feedbacks). Nesse sentido faz-se necessário refletir sobre a importância do trabalho do professor vinculado aos seus aspectos emocionais. Perrenoud (2002) traz a contribuição de que a escola também precisa ser um local onde o profissional possa trabalhar seus medos e emoções auxiliando, dessa forma, o seu desenvolvimento não só no aspecto profissional, mas da pessoa e de sua identidade.

Além disso, há de se pensar em um local de trabalho, como aponta Clot (2006), para um sistema que esboce as relações dos homens entre si para agir no mundo e, nesse sentido, advém a necessidade, apontada pelo autor, de um sistema múltiplo que possa comportar vários cenários e, por conseguinte, várias formas de agir. Cabe, portanto, a reflexão da escola como um contexto de múltiplos cenários com os quais os professores devem saber lidar, agir e pensar para, então, poderem criar um cenário de qualidade não só para os alunos, mas para toda a equipe escolar.

\section{Referências}

Bolsoni-Silva, A. T. (2010). Habilidades Sociais educativas do professor e sua relação com o repertório comportamental de crianças. Em V. L. M. F. Capellini \& O. M. P. R. Rodrigues (Orgs.), Práticas pedagógicas inclusivas: da criatividade à valorização das diferenças (Vol 5, pp. 147-181). Bauru, UNESP/FC/MEC.

Caballo, V. E. (2014). Manual de avaliação e treinamento das habilidades sociais (S. M. Dolinsky, Trad.) São Paulo: Santos. (Trabalho original publicado em 2003).

Caldeira, A. M. S. \& Zaidan, S. (2010). Prática pedagógica. Em D. A. Oliveira, A. C. Duarte \& L. M. F. Vieira (Org.). Dicionário: trabalho, profissão e condição docente (Vol. 1) Belo Horizonte, GESTRADO/ FaE/UFMG

Clot, Y. (2006). A função psicológica do trabalho. Petrópolis, RJ: Vozes.

Cunha, A. E. (2011). Práticas Pedagógicas para a inclusão e diversidade. Rio de Janeiro: Wak Editora.

Del Prette, Z. A. P. \& Del Prette, A. (1998). Habilidades sociais do professor em sala de aula: um estudo de caso. Psicologia Reflexão e Crítica, 11 (3), 0.

Del Prette, Z. A. P. \& Del Prette, A. (2012). Psicologia das habilidades sociais: terapia, educação e trabalho. Petrópolis, RJ: Vozes.

Del Prette, Z. A. P. \& Del Prette, A. (2013a). Psicologia das Habilidades Sociais na Infância: teoria e prática. Petrópolis, RJ: Vozes.

Del Prette, Z. A. P. \& Del Prette, A. (2013b). Psicologia das relações interpessoais: Vivências para o trabalho em grupo. Petrópolis, RJ: Vozes.

Del Prette, Z. A. P., Ferreira, B. C., Dias, T. P., \& Del Prette, A. (2015). Habilidades Sociais ao longo do desenvolvimento: perspectivas de intervenção em saúde mental. Em S. G. Murta, C. França-Leandro, K. B. Santos, \& L. Polejack (Orgs.), Prevenção e Promoção em Saúde Mental: Fundamentos, Planejamentos e Estratégias de Intervenção (Vol.1, pp. 318-340). Novo Amburgo, Sinopsys.

Gast, D. L. (2010). Single subject research methodology in behavioral sciences. New York, NY: Routledge.

Libâneo, J. C. (2013). Didática. São Paulo: Cortez.

Marques, L. P. (2001). O professor de alunos com deficiência mental: concepções e prática pedagógica. Editora UFJF.

Moros, M. \& Luna, S. V. (2013). Professor - o profissional do ensino! 
Reflexões do ponto de vista behaviorista/comportamental. Psicologia da Educação, 36, 115-121.

Perrenoud, P. (2002). A prática reflexiva no ofício do professor: profissionalização e razão pedagógica. Porto Alegre: Artmed.
Rosin-Pinola, A. R. (2009). Programa de Habilidades Sociais Educativas: Impacto sobre o repertório de professores e de alunos com necessidades educacionais especiais. Tese de Doutorado, Universidade de São Paulo, Ribeirão Preto, SP.

Recebido em: 26/01/2016

Aprovado em: 29/11/2016

\section{Sobre as autoras}

Tatiane Cristina Rodrigues Lessa (taticrisrl@hotmail.com)

Mestranda no Programa de Pós-Graduação em Educação Especial da Universidade Federal de São Carlos, especialista em Psicologia Analítica pela Universidade Estadual de Campinas e psicóloga pela Universidade Federal de São Carlos.

Natalia Costa de Felicio (natifelicio@msn.com)

Mestranda no Programa de Pós-Graduação em Educação Especial da Universidade Federal de São Carlos e pedagoga pela Universidade de São Paulo.

Maria Amélia Almeida (ameliama@terra.com.br)

Pós-doutora em educação pelo University of Georgia, UGA, professora associada no Departamento de Psicologia, licenciatura em Educação Especial da Universidade Federal de São Carlos (UFSCar). Professora do Programa de Pós-graduação em Educação Especial da UFSCar. 